ISSN 1409-2441

www.ucr.ac.cr
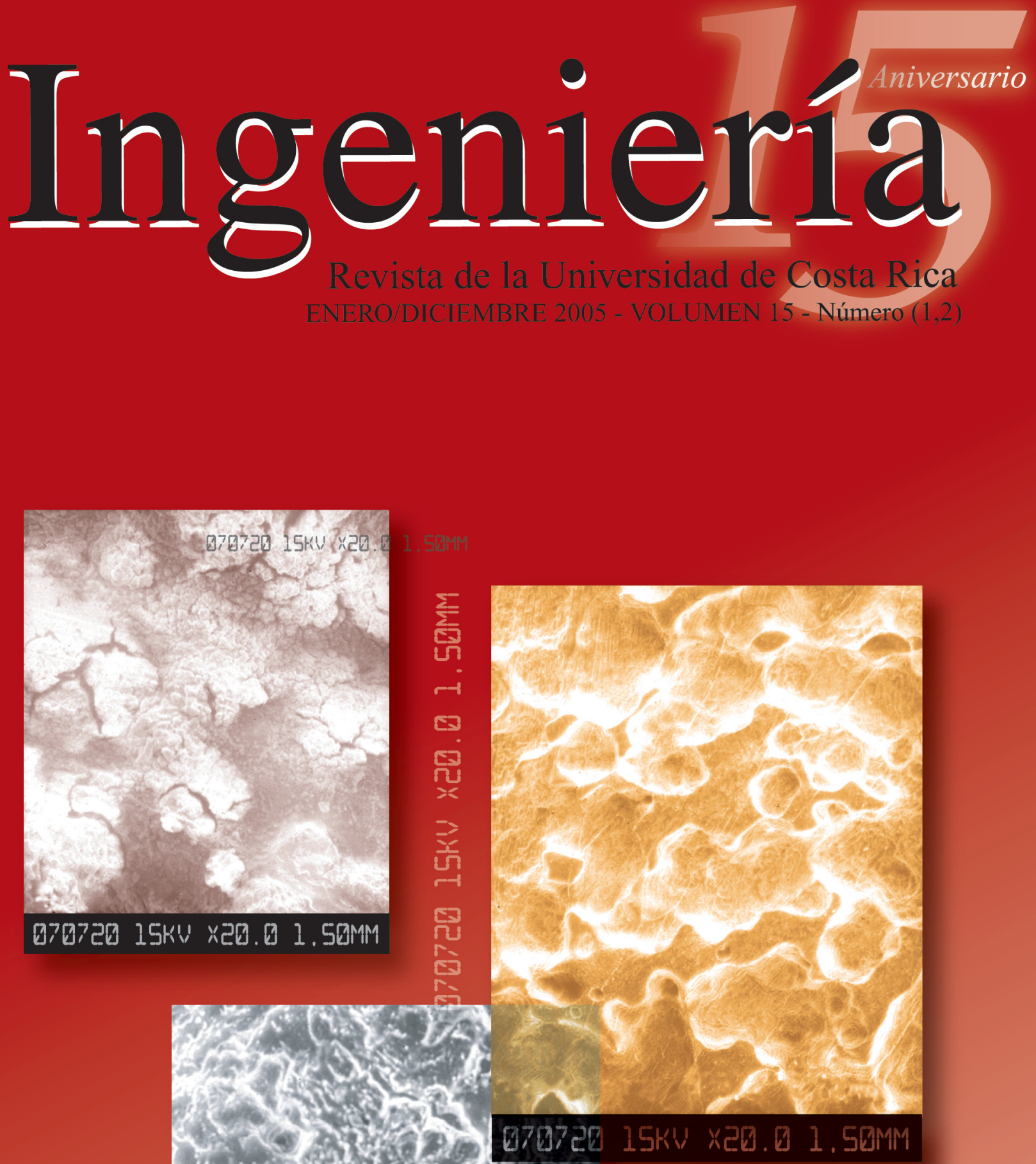

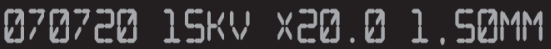

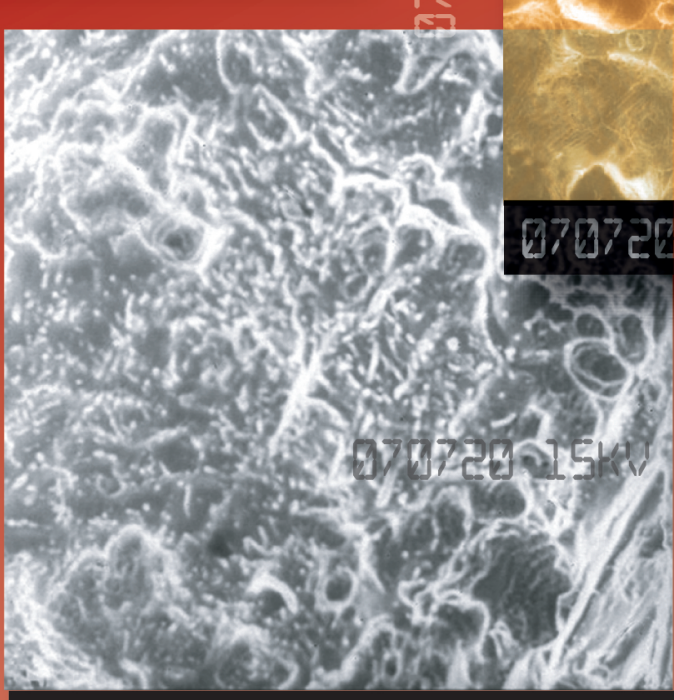

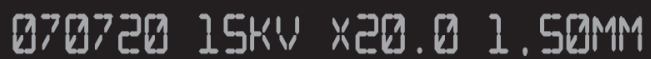




\title{
DESCRIPCIÓN Y CUANTIFICACIÓN DEL DAÑO Y DESPLAZAMIENTOS EN MARCOS DE CONCRETO REFORZADO A ESCALA $1 / 3$.
}

\author{
Miguel F. Cruz Azofeifa, Randall Vega Ramírez, Ronald Jiménez Castro
} Brenda Ramírez Dondi, Juan I. Boza Castro

\begin{abstract}
Resumen
Este trabajo muestra los resultados de los ensayos de elementos viga, de elementos columna y de marcos de concreto reforzado de dos niveles, construidos a escala $1 / 3$. Fueron ensayados bajo un sistema de desplazamientos laterales cíclicos alternantes. Las características de los elementos ensayados corresponden a las de los mismos elementos de los marcos. Las dimensiones de los marcos son de $2 \mathrm{~m}$ de ancho por 2,26 $\mathrm{m}$ de alto, $1,13 \mathrm{~m}$ por cada nivel. Los elementos ensayados son en realidad medios elementos, bajo el supuesto de que su punto de inflexión se encuentra a la mitad de su longitud.

Se calcula para cada espécimen ensayado y en cada ciclo de carga el índice de daño de Park y Ang, el desplazamiento relativo y la energía plástica disipada. Se observó que los elementos individuales mostraron mayor capacidad de deformación lateral que los marcos. Se pudo observar que los índices de daño para el daño leve, entendido este como agrietamiento menor a $1 \mathrm{~mm}$, no superan el valor de 0,28 y que el daño severo, que contiene agrietamientos mayores a $3 \mathrm{~mm}$ y desprendimiento del concreto, empieza a presentarse para índices de daño mayores a 0,60.

El daño severo se presenta para valores de desplazamiento relativo mayor al $4 \%$, mientras que el daño moderado se presenta para valores del orden del $2 \%$. Un $1 \%$ o menos de desplazamiento relativo implica daño leve. La energía plástica disipada normalizada a la energía máxima plástica estática, alcanzó valores de 2 , para condiciones de daño severo y valores menores que 1 , para condiciones de daño moderado.

Para predecir el comportamiento elástico inicial de los marcos debió utilizarse un EIeq = 0,65 Ec Ig en las secciones de columnas y un Eleq $=0,27 \mathrm{Ec}$ Ig en las secciones de vigas. Un análisis tipo push-over que utiliza los valores iniciales de la rigidez antes mencionados predice la envolvente de la curva histerética carga-desplazamiento con valores menores a los reales en el orden de un $30 \%$.
\end{abstract}

Palabras clave: concreto reforzado, cálculo de daño, modelos a escala.

\begin{abstract}
The results of the tests performed on beam and column specimens and on $\mathrm{R} / \mathrm{C}$ frames, built in a reduced $1 / 3$ scale, are presented in this work. The frames were two level frames, and the elements had the same characteristics of correspondent element of the frame. The elements and the frames were subjected to lateral cyclic displacements.

The tested element lengths were one half the length of the correspondent element of the frame; this was so because it was supposed that the inflexion point was located at the center of the element length..

The Park and Ang damage index was calculated for each specimen at each cycle of loading, as well as the relative displacement and the plastic dissipated energy. It was observed that the elements showed a deformation capacity greater than that of the frames. Light damage (thin cracks less than $1 \mathrm{~mm}$ ) showed a damage index less than 0,28. Severe damage (cracks wider than $3 \mathrm{~mm}$ and cover falling) showed a damage index greater than 0,60 .
\end{abstract}

Severe damage was attained when the relative displacement was greater than $4 \%$. Moderate damage was obtained for relative displacements around $2 \%, 1 \%$ or less of relative displacement means light damage. The normalized plastic dissipated energy with respect to the maximum plastic static energy is around 2 for severe damage and less than 1 for moderate damage.

It was necessary to use EIeq=0,65 EcIg for columns and EIeq=0,27 EcIg for beams to predict the elastic initial behavior of the frames. The push-over analysis, which used initial stiffness values, predicts the envelope of the hysteretic loaddisplacement curve with $30 \%$ lower values than those of the test.

Key words: reinforced concrete, damage calculations, scaled models 


\section{INTRODUCCIÓN}

El presente trabajo muestra los procedimientos y resultados de ensayos realizados sobre elementos y marcos de concreto reforzado, construidos a escala $1 / 3$ y sometidos a cargas laterales alternantes hasta la falla estructural.

El objetivo de esta investigación es correlacionar el valor del índice de daño, calculado con la expresión de Park y Ang (Park \& Ang, 1985), con la descripción cualitativa del daño observable. También se correlaciona el índice de daño con los desplazamientos relativos de los especímenes y con la energía disipada durante el ensayo. Adicionalmente, se requiere conocer cuál es el valor de EIcq (módulo de elasticidad por momento de inercia) de los elementos a utilizar en los análisis estructurales, elásticos y elasto-plásticos, para determinar los desplazamientos laterales de los marcos ensayados.

Los especímenes son cargados únicamente con carga lateral, así que los efectos de carga axial no son considerados, y por ende, los efectos P- $\Delta$ no están incluidos en los ensayos ni en los análisis. Se trabaja con modelos planos y los ensayos se realizan introduciendo desplazamientos laterales incrementados de manera lenta con el fin de que no haya efectos dinámicos.
Los especímenes son construidos con materiales y la mano de obra común de las obras de concreto reforzado existente en Costa Rica.

El diseño de los marcos se realizó siguiendo los lineamientos del (Reglamento para Construcciones de Concreto Estructural y Comentarios ACI 318, 1999) y del (Código Sísmico de Costa Rica, 1986).

Las dimensiones de los marcos se muestran en la Figura 1a de tal manera que la altura de los pisos es de 1,13 $\mathrm{m}$ y el ancho del vano de viga es de 2,00 m. Las columnas tienen una sección de $15 \times 15 \mathrm{~cm}$ y las vigas de $13 \times 20 \mathrm{~cm}$. La Figura $1 \mathrm{~b}$ muestra el marco experimental.

Los refuerzos correspondientes, se muestran en la Figura 2a incluyendo el refuerzo del nudo. Los refuerzos de estos elementos son el resultado de diseñar el marco para una cortante basal de 3,1 ton distribuida con un 1/3 del total en el segundo nivel y $2 / 3$ del total en el primer nivel.

Los elementos construidos y fallados individualmente, corresponden a medios elementos obtenidos del diseño del marco original. De esta manera el elemento columna tiene una longitud de $50 \mathrm{~cm}$ y los elementos viga tienen una longitud de $90,5 \mathrm{~cm}$. Los materiales utilizados en el diseño y construcción de los especímenes (Vega, 2000),

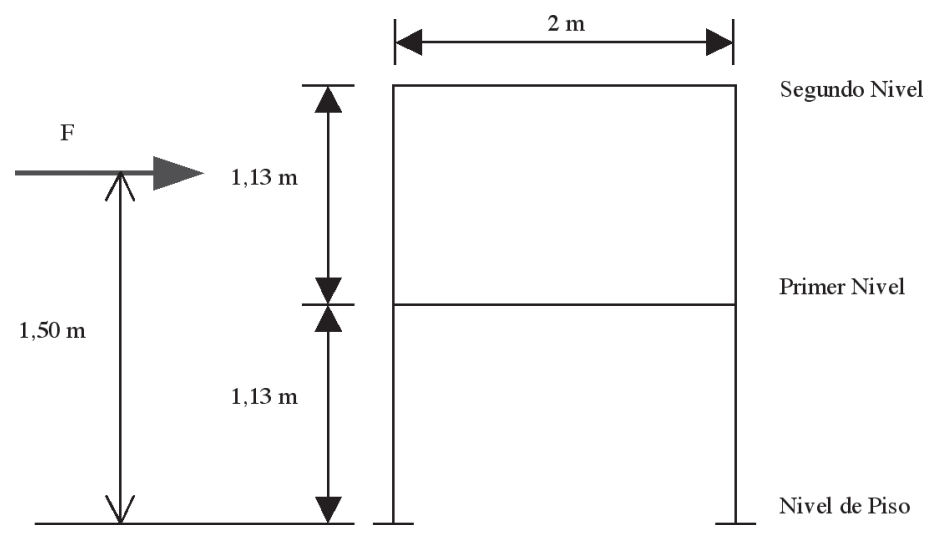

Figura 1a. Modelo de marco y punto de aplicación de la fuerza 


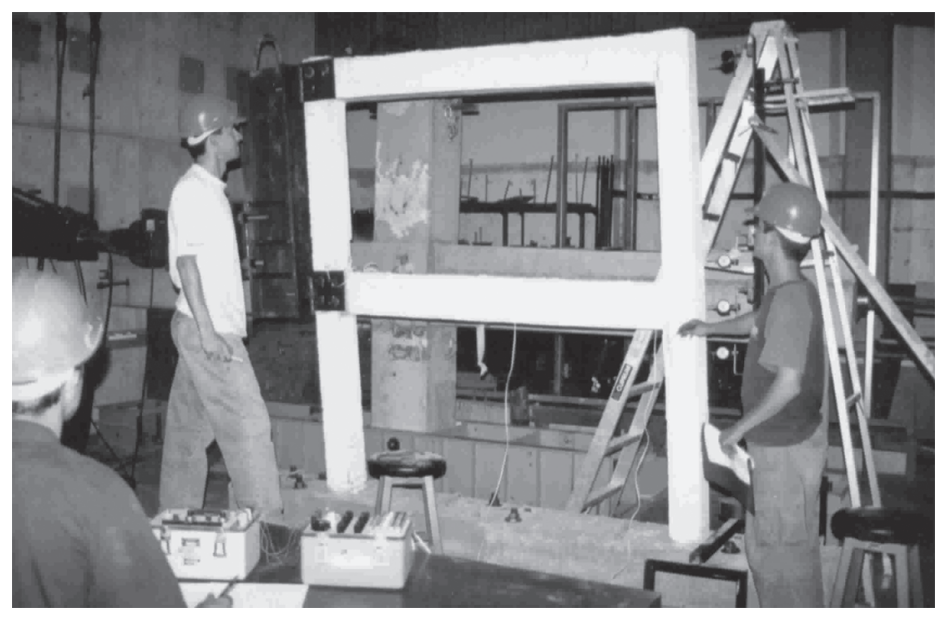

Figura 1.b Modelo real del marco en un estado de carga

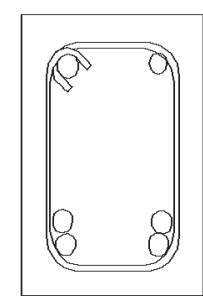

Viga primer nivel $13 \times 20 \mathrm{~cm}$ 6\#3. A ros \#2 (a) $4 \mathrm{~cm}$

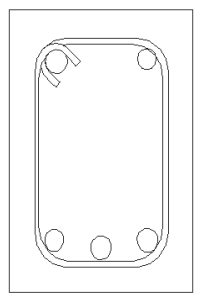

Viga segundo nivel $13 \times 20 \mathrm{~cm}$

5\#3. Aros \#2@4cm

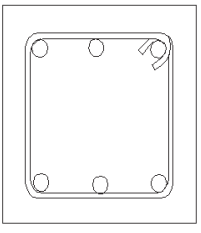

Columna $15 \times 15 \mathrm{~cm}$ 6\#4. Aros \#2@5cm

Figura 2a. Secciones De Vigas Y Columnas

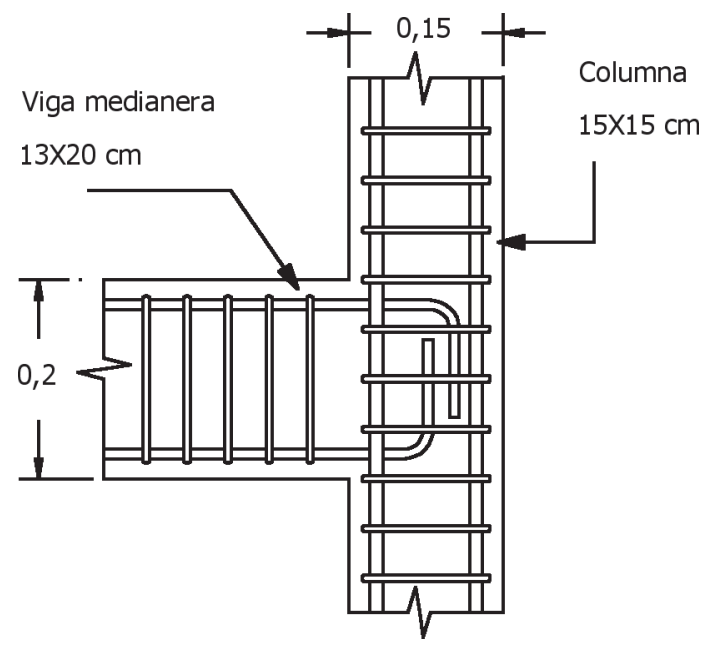

Figura 2.b Detalle del nudo 
(Jiménez, 2003), (Boza, 2002) y (Ramírez, 1992) son de concreto de $210 \mathrm{~kg} / \mathrm{cm}^{2}$ y acero de refuerzo grado 40 .

\section{ENSAYOS Y RESULTADOS DE LOS ELEMENTOS INDIVIDUALES.}

Se construyeron dos espécimenes de los elementos individuales. Es decir se construyeron dos espécimenes de ensayo por cada modelo a analizar, y se realizaron dos ciclos de carga para cada valor de desplazamiento lateral considerado. El Cuadro 1 muestra los valores de desplazamiento lateral aplicados a cada espécimen de los modelos de viga de primer nivel, viga de segundo nivel y columna.

En la viga del primer nivel se aplicaron ciclos de carga de diferentes valores en desplazamientos positivos y negativos, esto para considerar que la viga tiene diferente refuerzo en las caras de tracción correspondientes a momento positivo y momento negativo. Los dos espécimenes fueron ensayados para los mismos valores de desplazamiento lateral. Obsérvese que el primer espécimen toleró un desplazamiento relativo último de un $13 \%$.

En la viga del segundo nivel uno de los espécimenes fue ensayado para ciclos de carga y descarga simétricos a pesar de la diferencia de refuerzo para momento positivo y negativo. El otro espécimen fue cargado con ciclos de diferente valor de desplazamiento positivo y negativo. Estos espécimenes de viga también alcanzaron valores de desplazamiento relativo del orden de $13 \%$.

Los espécimenes de columna fueron cargados con ciclos simétricos de desplazamiento y toleraron desplazamiento relativos superiores al $12 \%$.

Los ciclos de carga se detuvieron cuando se observó una caída de la resistencia y cuando el daño observado era evidentemente severo.

La Figura 3 muestra fotografías del primer espécimen de la viga del segundo nivel durante el ciclo de 5,4 cm y durante el ciclo de $12,4 \mathrm{~cm}$. Obsérvese el pandeo del refuerzo durante el último ciclo de carga.

Las Figuras 4, 5 y 6 muestran las curvas histeréticas de carga y descarga de los espécimenes de viga del primer nivel, viga del segundo nivel y del primer modelo de columna. Obsérvese que las vigas mantienen una curva histerética abierta y estable hasta tanto no se introduzcan los desplazamientos laterales superiores al $10 \%$. No sucede lo mismo en las curvas de las columnas, las que presentan una curva con estrangulamiento en la parte central (fenómeno conocido como shear pinching). Esto

Cuadro 1. Desplazamiento de elementos

\begin{tabular}{|c|c|c|c|c|c|c|c|c|}
\hline \multirow[t]{5}{*}{ Elemento } & Modelo & $\begin{array}{l}\text { Ciclo de } \\
\text { Carga }\end{array}$ & Elemento & Modelo & $\begin{array}{c}\text { Ciclo de } \\
\text { Carga }\end{array}$ & Elemento & Modelo & $\begin{array}{c}\text { Ciclo de } \\
\text { Carga }\end{array}$ \\
\hline & & $0,1 /-0,1$ & & & $0 /-0,4$ & & & $0,8 /-0,8$ \\
\hline & & $0,4 /-0,4$ & & & $0,8 /-1,6$ & & & $2,0 /-2,0$ \\
\hline & 1 & $1,6 /-1,6$ & & 1 & $3,2 /-6,4$ & & 1 & $4,0 /-4,0$ \\
\hline & & $6,4 /-6,4$ & & & $6,4 /-12$ & & & $6,0 /-6,0$ \\
\hline \multirow[t]{5}{*}{ Viga 2} & & $12,8 /-12,8$ & Viga 1 & & & Columna & & $8,0 /-8,0$ \\
\hline & & $0 /-0,4$ & & & $0 /-0,4$ & & & $0,4 /-0,4$ \\
\hline & & $0,8 /-1,6$ & & & $0,8 /-1,6$ & & & $2,4 /-2,4$ \\
\hline & 2 & $4 /-6,4$ & & 2 & $3,2 /-6,4$ & & 2 & $4,4 /-4,4$ \\
\hline & & $8,4 /-12,4$ & & & $\begin{array}{l}6,4 /- \\
10,4\end{array}$ & & & $6,4 /-6,4$ \\
\hline
\end{tabular}



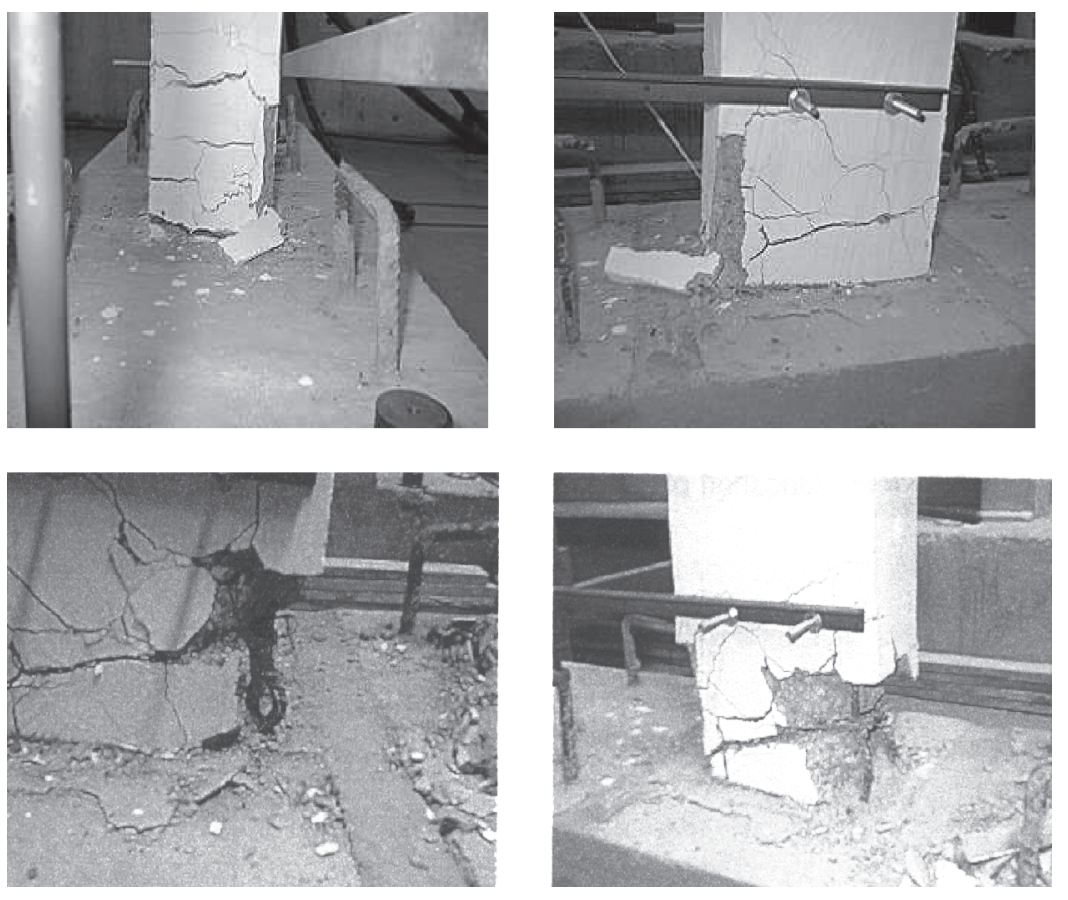

Figura 3. Nivel de daño moderado y severo en viga del segundo nivel

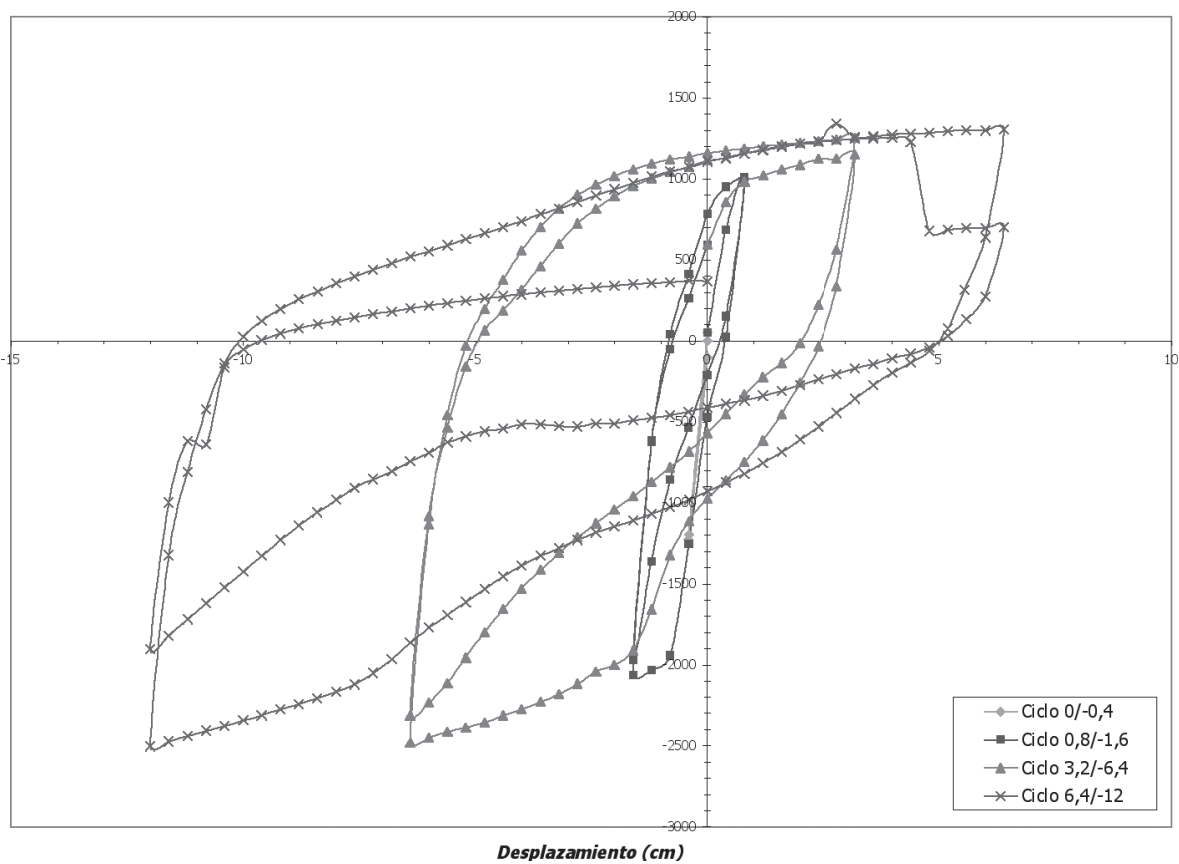

Figura 4. Curva de histéresis primer modelo, viga primer nivel e idealización elasto-plástica. 


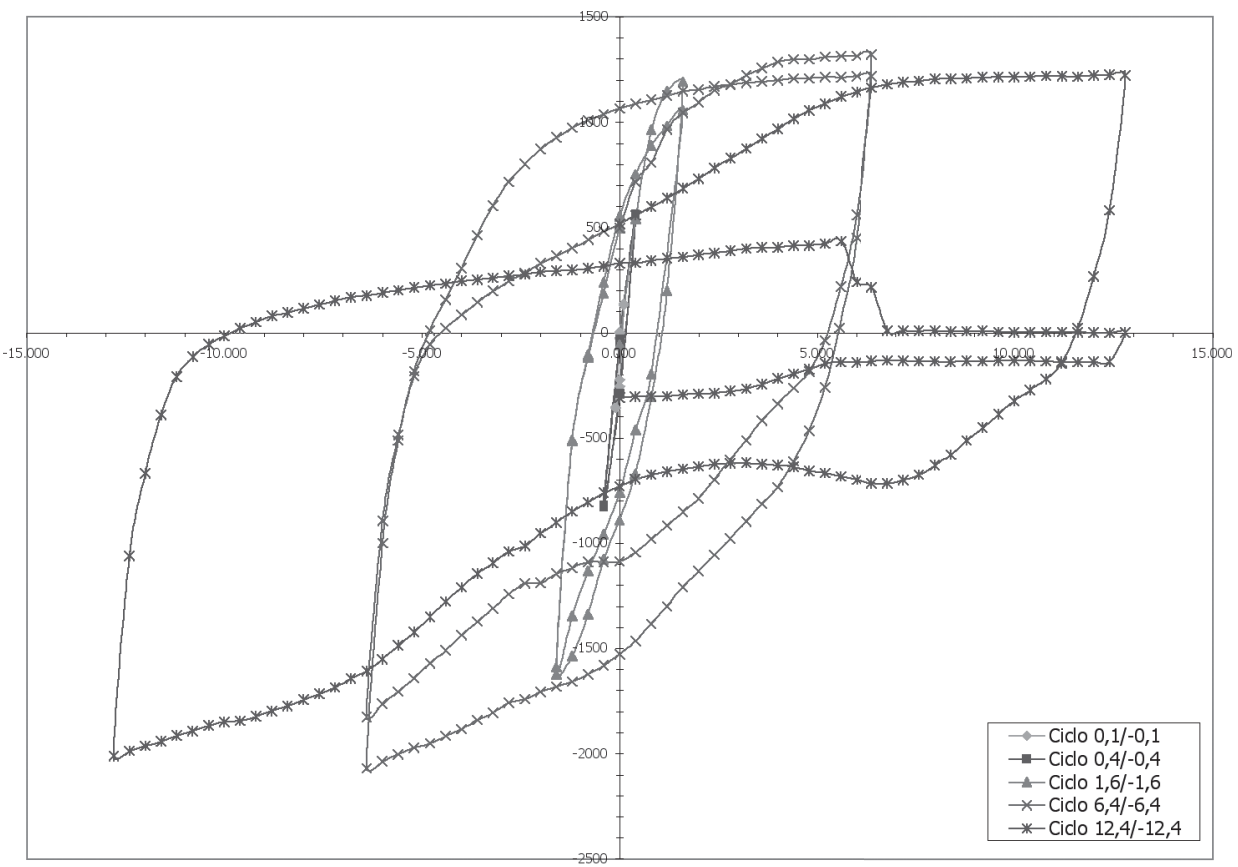

Desplazamiento $(\mathrm{cm})$

Figura 5. Curva de histéresis primer modelo, viga segundo nivel e idealización elasto-plástica.

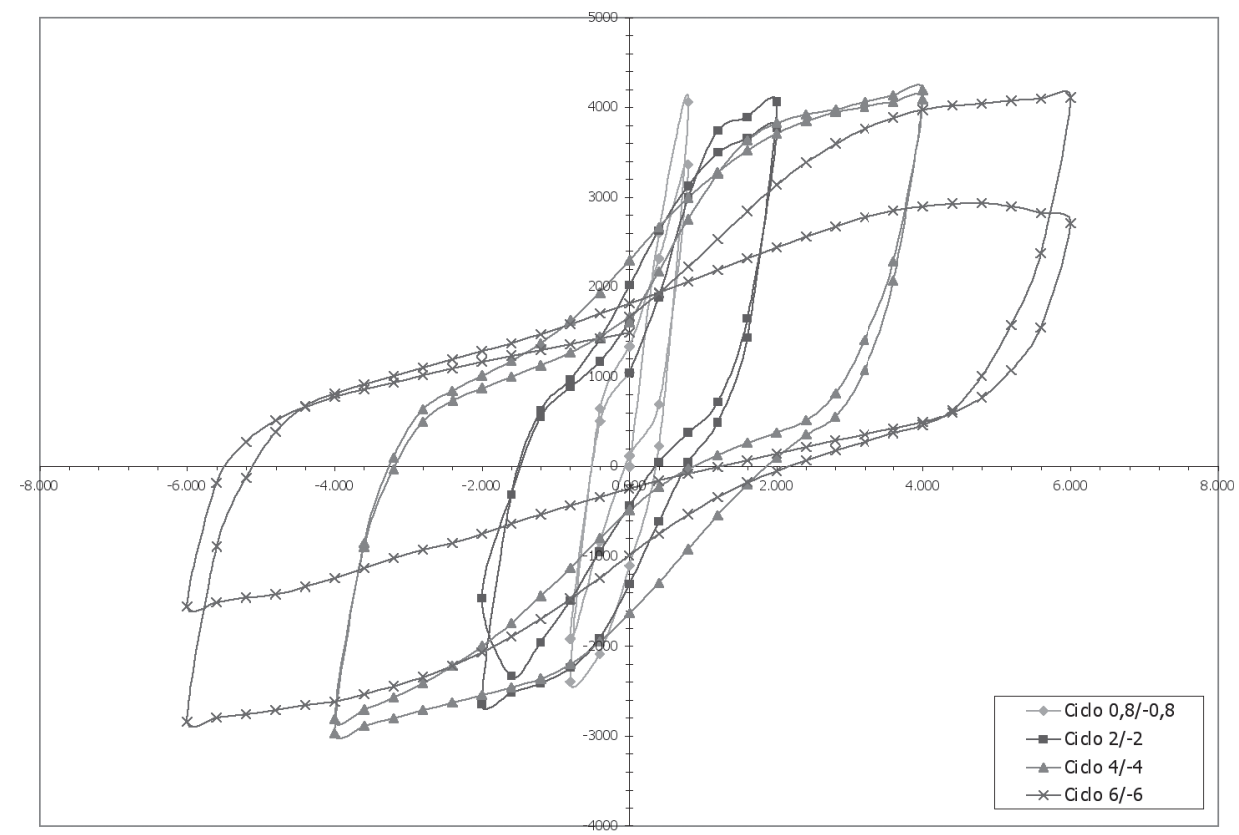

Desplazamiento $(\mathrm{cm})$

Figura 6. Curva de histéresis, primer modelo de columna. 
es producido, probablemente, por el efecto del cortante en la sección transversal más solicitada.

El porcentaje de refuerzo transversal en vigas resultó en $\rho_{\mathrm{V}}=0.0168$ y en las columnas en 0,0136 . La separación de aros; entre altura efectiva, s/d, en vigas fue de 0,23 y en columnas de 0,40. Este último valor en superior a 0,25 que es lo exigido por la norma. El no respetar esta reglamentación puede ser la causa del estrangulamiento de las curvas histeréticas de las columnas.

\section{ENSAYOS Y RESULTADOS DE LOS MARCOS}

En el caso de los marcos, también se construyeron dos espécimenes para ser ensayados. Uno de ellos (marco 1) fue sometido a ciclos de carga y descarga en una sola dirección, es decir, de cero al desplazamiento máximo y luego descargado hasta cero desplazamiento. El marco 2 se cargó en ambas direcciones, es decir, de cero al desplazamiento máximo y luego volvió a cero, para ser cargado en el sentido opuesto hasta el desplazamiento máximo.

Los desplazamientos de cada ciclo en cada espécimen se muestran en el Cuadro 2.
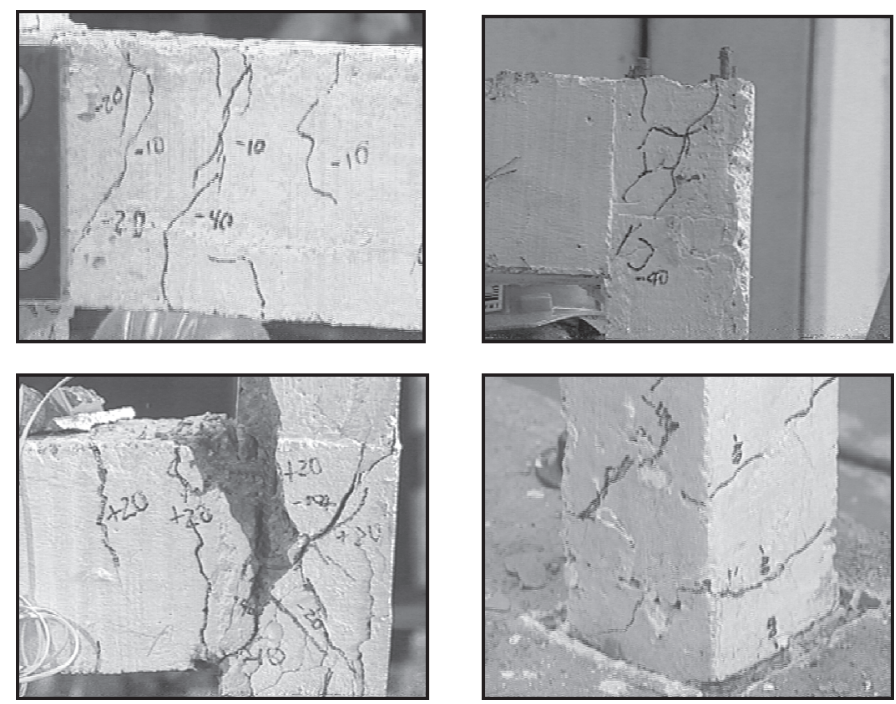

Figura 7. Nivel de Daño Moderado y Severo en marco 1 
lateral y a los $16 \mathrm{~cm}$ de desplazamiento lateral del marco 1.

La Figura 8 muestra las curvas histeréticas del marco 1 y del marco 2 . Obsérvese que la capacidad última de cada marco es más o menos el mismo valor. Este valor es el doble de la capacidad del segundo espécimen de columna, situación que era totalmente esperable. La capacidad última del marco a nivel de cortante basal, resultó ser del orden del doble de la carga de diseño.

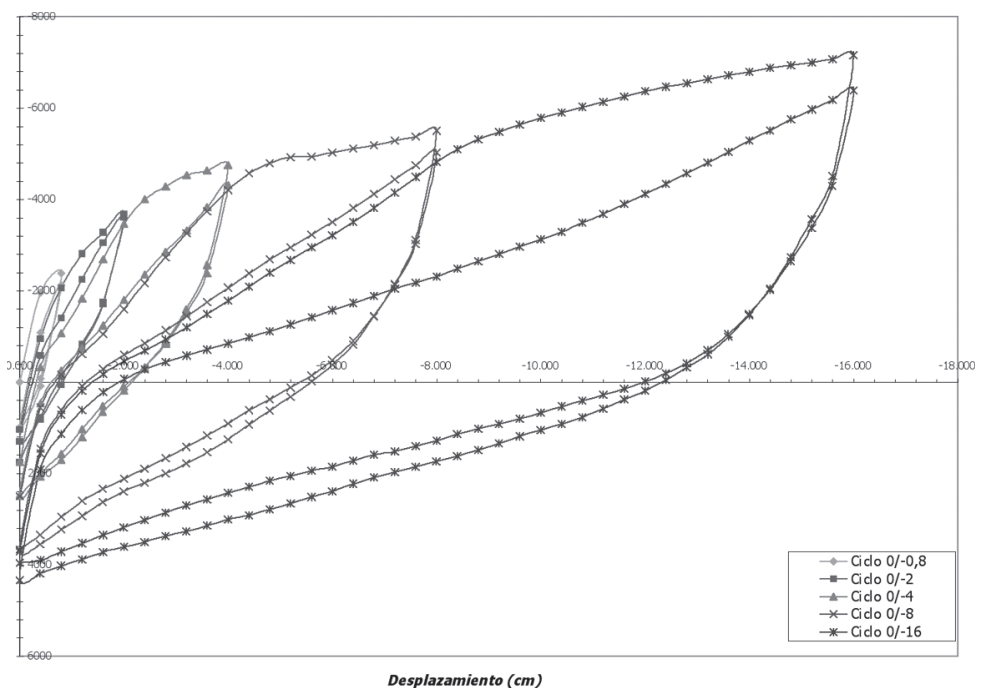

Figura 8a. Marco 1.

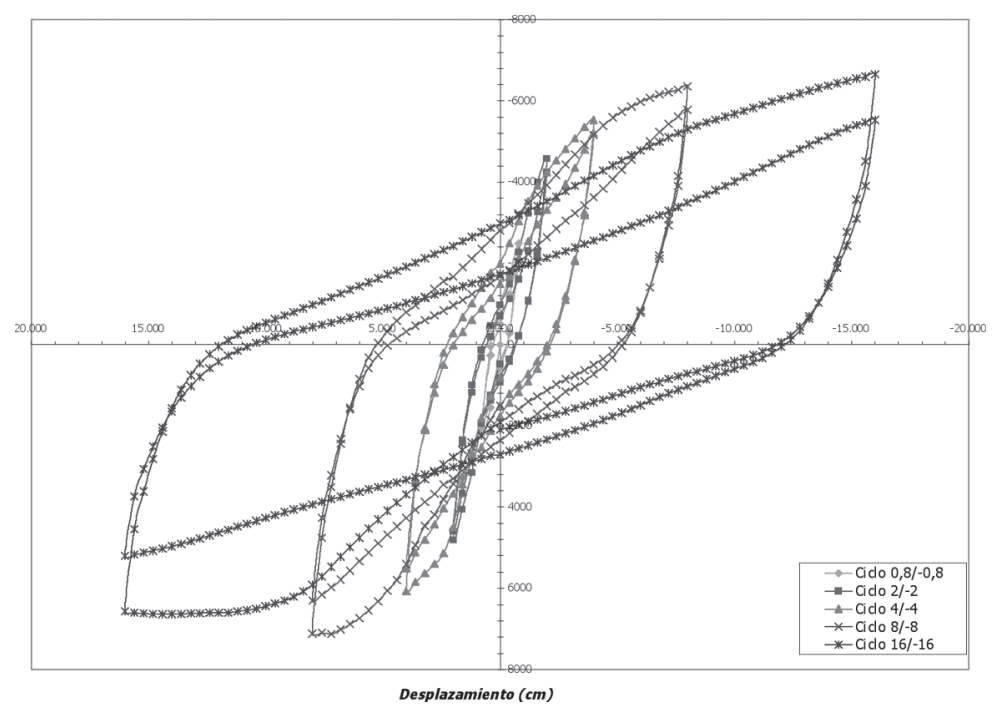

Figura 8b. Marco 2

Figura 8. Curvas de histéresis de marcos e idealización elasto-plástica. 
Obsérvese también que la curva histerética del marco 2 muestra la misma característica de estrangulamiento en la cintura, debido al cortante que presentaron las columnas individuales. Las columnas del marco también presentaron agrietamiento en cortante importante, al igual que las columnas individuales. Las vigas del marco presentaron únicamente agrietamiento de flexión. La Figura 9 muestra la columna aislada y la columna del marco con importante agrietamiento en cortante. Esto muestra la importancia que tiene el confinamiento de las columnas en el comportamiento del marco.

En todas las curvas histeréticas anteriormente mostradas, para los marcos y para los elementos, se presenta también la curva elasto-plástica equivalente que define $\delta_{y}$ y $Q_{y}$. Esta curva (Chopra, 1995) mantiene la rigidez inicial y encierra un área igual al área de la curva envolvente del ensayo.

\section{EVALUACIÓN DE LOS ID Y COMPARACIÓN CON DAÑO DESCRIPTIVO}

La expresión del índice de daño de Park y Ang (Park y Ang, 1985) contiene aspectos de desplazamiento lateral y aspectos de energía plástica disipada. Esta expresión es como sigue:
$I D=\frac{\delta_{m}}{\delta_{u}}+\frac{\beta}{Q_{y} \delta_{u}} E_{p}$

donde:

$\delta_{m}$ : es la deformación que se experimenta en el ensayo,

$\delta_{u}$ : es la deformación máxima que puede tolerar el espécimen bajo carga estática,

$Q_{y}$ : es la resistencia a la cedencia,

$\beta$ : es un factor de ajuste considerado en este trabajo como $0.15, \mathrm{y}$

$E_{p}$ : es la energía disipada acumulada.

En el caso de los elementos individuales se ha utilizado un valor de $\delta_{u}$ como el valor medio entre el valor de cedencia del ensayo $\left(\delta_{u}\right)$ multiplicado por la ductilidad sugerida por Park y Ang (Park \& Ang, 1985) y el valor máximo del ensayo cíclico. En el caso de los marcos se ha utilizado un valor de $\delta_{u}$ igual al desplazamiento último del ensayo ya que el marco 1 muestra la envolvente del ensayo estático y el deplazamiento máximo del marco queda limitado por el comportamiento en las uniones viga columna que se estima similar, en el caso del marco 1, al del correspondiente ensayo estático.

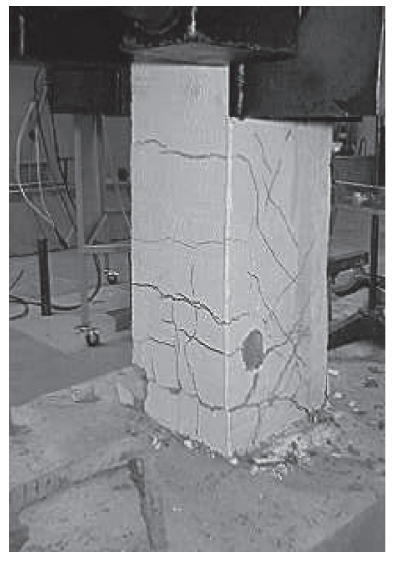

Columna Aislada

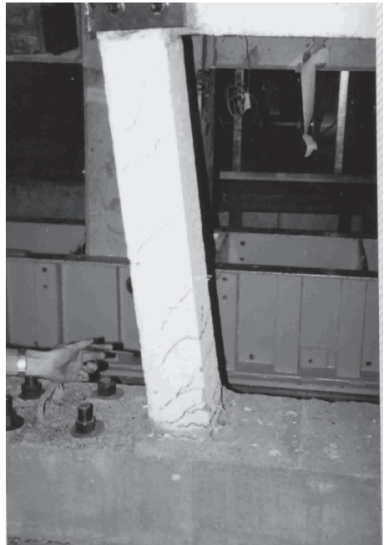

Columna en el marco

Figura 9. Agrietamientos similares en columnas 
Según lo descrito anteriormente, se calculan los ID para cada espécimen al final del segundo ciclo para cada nivel de desplazamiento. El Cuadro 3 muestra los resultados para los elementos individuales y el Cuadro 4 muestra los valores para los marcos. Obsérvese que el Cuadro 3 no muestra valores de ID mayores que 1 ya $\delta_{u}$ se consideró, en todos los casos, mayor que el $\delta_{m}$ del ensayo.
En el caso de los marcos los ID superan el valor de 1 ya que $\delta_{u}$ se supuso igual al $\delta_{m}$ del ensayo.

Esta última condición de ID demuestra que el mismo muy dependiente del $\delta_{u}$ y que la determinación apropiada de este último parámetro se hace necesaria para la correcta evaluación del ID.

\begin{tabular}{|c|c|c|c|c|}
\hline Elemento & Modelo & Ciclo De Carga & $\begin{array}{l}\text { Indice de } \\
\text { daño }\end{array}$ & $\begin{array}{c}\delta_{R E L}(\%) \\
0,11\end{array}$ \\
\hline \multirow{8}{*}{ V2 } & \multirow{5}{*}{1} & $0,1 /-0,1$ & 0,003 & \multirow{2}{*}{$\begin{array}{l}0,11 \\
0,44\end{array}$} \\
\hline & & $0,4 /-0,4$ & 0,014 & \\
\hline & & $1,6 /-1,6$ & 0,063 & 1,76 \\
\hline & & $6,4 /-6,4$ & 0,324 & \multirow{2}{*}{$\begin{array}{c}7,05 \\
14,10\end{array}$} \\
\hline & & $12,8 /-12,8$ & 0,620 & \\
\hline & \multirow{4}{*}{2} & $0 /-0,4$ & 0014 & \multirow{2}{*}{$\begin{array}{l}0,44 \\
1,76\end{array}$} \\
\hline & & $0,8 /-1,6$ & 0070 & \\
\hline & & $4 /-6,4$ & 010 & 7,05 \\
\hline \multirow{10}{*}{ V1 } & & $8,4 /-12,4$ & 0691 & 13,66 \\
\hline & \multirow{4}{*}{1} & $0 /-0.4$ & 0,013 & \multirow{2}{*}{$\begin{array}{l}0,44 \\
1,77\end{array}$} \\
\hline & & $0,8 /-1,6$ & 0,059 & \\
\hline & & $3,2 /-6,4$ & 0.270 & \multirow{2}{*}{$\begin{array}{c}7,08 \\
13,27\end{array}$} \\
\hline & & $6,4 /-12$ & 0.563 & \\
\hline & \multirow{4}{*}{2} & $0 /-0.4$ & 0.018 & 0,44 \\
\hline & & $0,8 /-1,6$ & 0,084 & 1,77 \\
\hline & & $3,2 /-6,4$ & 0,403 & 7,08 \\
\hline & & $6,4 /-10,4$ & 0,748 & 11,51 \\
\hline & & $0,8 /-0,8$ & 0.055 & 1,60 \\
\hline & & $2 /-2$ & 0164 & 4,00 \\
\hline & 1 & $4 /-4$ & 0378 & 8,00 \\
\hline & & $6 /-6$ & 0.618 & 12,00 \\
\hline $\mathrm{C}$ & & $8 /-8$ & 0.787 & 16,00 \\
\hline & & $0,4 /-0,4$ & 0.031 & 0,80 \\
\hline & & $2,4 /-2,4$ & 0.263 & 4,80 \\
\hline & 2 & $4,4 /-4,4$ & 0552 & 8,80 \\
\hline & & $6.4 /-6.4$ & 0,778 & 12,8 \\
\hline
\end{tabular}

Fuente: El autor 
Cuadro 4. Índices de Daño por ciclo de carga en los marcos.

$\begin{array}{cccc}\text { Elemento } & \text { Ciclo de Carga } & \text { Índice de daño } & \delta_{R E L}(\%) \\ & 0 /-0,8 & 0,052 & 0.53 \\ & 0 /-2 & 0,136 & 1.33 \\ \text { Marco 1 } & 0 /-4 & 0,280 & 2.66 \\ & 0 /-8 & 0,620 & 5.33 \\ & 0 /-16 & 1,354 & 10.66 \\ & -0,8 / 0,8 & 0,052 & 0.53 \\ \text { Marco 2 } & -2 / 2 & 0,141 & 1.33 \\ & -4 / 4 & 0,336 & 2.66 \\ & -8 / 8 & 0,781 & 5.33 \\ & -16 / 16 & 1,715 & 10.66\end{array}$

En el caso de los elementos individuales se ha tomado el valor medio antes mencionado, pues las ductilidades sugeridas por Park y Ang (Park y Ang, 1985) resultan valores excesivos de aparente difícil obtención con el concreto reforzado. El valor medio utilizado, en todos los casos, resultó en una ductilidad del orden del doble de la del ensayo cíclico.

Obsérvese que los índices de daño superiores a 0,4 se alcanzaron para desplazamientos relativos superiores al $7 \%$ en las vigas y superiores al 8 $\%$ en las columnas. Desplazamientos pequeños del orden del $1 \%$ apenas si causaron índices de daño del orden de 0,05 .

Después de calculado el ID se correlacionó el mismo con el daño descriptivo.

El daño descriptivo es clasificado en leve, moderado y severo, asociado cada estado con un tamaño de grietas y con condiciones en el concreto exterior y del acero de refuerzo. Se asigna un color a cada condición de daño, de esta manera se establece lo siguiente:

- Daño leve: grietas pequeñas, casi despreciables, sección intacta. Color verde.
- Daño moderado: grietas más grandes, de tamaño de $1 \mathrm{~mm}$, inicio de aplastamiento en el concreto. Daño reparable (Park y Ang, 1985). Color amarillo.

- Daño severo: grietas muy grandes mayores de $1 \mathrm{~mm}$, concreto aplastado, recubrimiento suelto o caído, refuerzo visible. Daño irreparable (Park y Ang, 1985). Color rojo.

La Figura 10 muestra la correlación del valor del ID con el daño descriptivo y utilizando el patrón de colores, y para los diferentes índices calculados, ya sea en vigas y columnas individuales y para los marcos. Se han trazado dos límites arbitrarios en 0,20 y 0,6, para determinar los cambios entre leve y moderado y entre moderado y severo. El límite (Park y Ang, 1985) entre moderado y severo está en ID > 0,40 lo que concuerda bien con lo obtenido con las vigas y los marcos, no así con las columnas, que presentan índices de daño mayores a 0,4 aun cuando se puede describir su condición con daño moderado.

La línea de ID igual a 0,6 se trazó arbitrariamente para definir el daño severo (Park y Ang, 1985), el daño extensivo se presenta cuando los índices están entre 0,5 y 1,0. Según los resultados de este 
trabajo, el daño severo se presenta en promedio para ID mayor a 0,6 .

\section{CORRELACIÓN DEL DAÑO CON LOS DESPLAZAMIENTOS LATERALES Y CON LA ENERGÍA DISIPADA}

Para correlacionar el daño con la energía disipada se define el término energía plástica normalizada como sigue:

$E_{\text {plástica estática }}=Q_{y} \delta_{u}$

siendo la $E_{\text {plastica-cíclica }}$ la acumulada del ensayo realizado y la $E_{\text {plástica-cíclica }}$ igual a

$E_{P N}=\frac{E_{\text {plástica }- \text { cíclica }}}{E_{\text {plástica }- \text { estática }}}$

la que define la energía máxima que puede absorber el elemento o la estructura si es cargada estáticamente desde cero hasta el desplazamiento último con comportamiento elasto-plástico.
La correlación del índice de daño con la energía plástica normalizada, se muestra en la Figura 11.

Es claro en esta Figura que mientras la energía plástica normalizada no supere el valor de 1 , el daño será moderado o leve.

Para valores de $E_{P N}$ entre 1 y 2 el daño será moderado o severo, y claramente, para valores de $E_{P N}$ mayores que 2 el daño será severo. A manera de resumen, se puede suponer que los ensayos cíclicos fueron capaces de disipar el doble de la energía que se disiparía en un ensayo estático llevado hasta los desplazamientos últimos.

En la Figura 12 se muestra la correlación del índice de daño con los desplazamientos relativos. Se muestra que el comportamiento de los marcos es muy diferente al de los elementos. Los elementos muestran una capacidad de deformación muy superior a la de los marcos. El daño severo para los elementos se alcanzó para deformaciones superiores al $12 \%$, mientras que en marcos el daño severo se alcanzó para deformaciones superiores al $4 \%$.

Es claro que deformaciones menores al $2 \%$ implican, en todos los casos, daño leve.

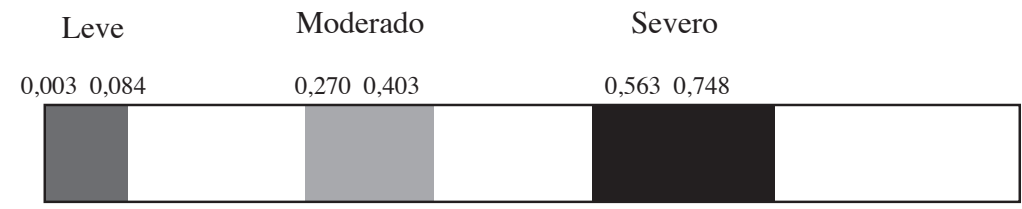

Rango índice daño - Vigas

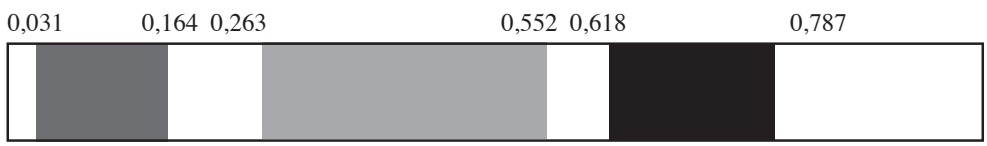

Rango índice daño - Columnas

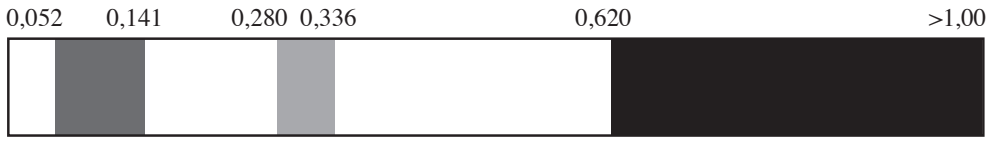

Rango índice daño - Marcos

Figura 10. Correlación del ID con el daño descriptivo. 


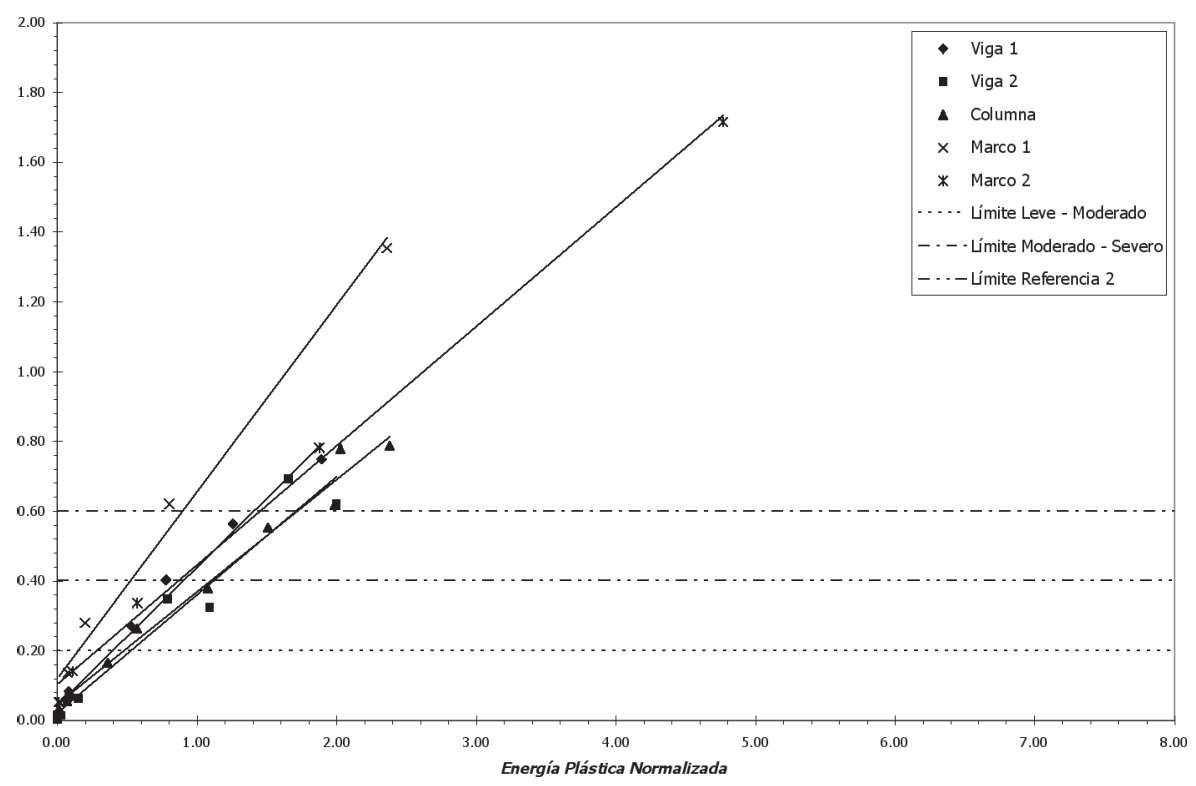

Figura 11. Indice de daño Vs energía plástica normalizada.

Se observa que el daño moderado en marcos se presenta para deformaciones del orden del $3 \%$, por lo tanto los límites de desplazamiento relativo (Park \& Ang, 1985) impuestos por las normas parecen ser muy conservadores.

Puede que la carga axial influya en limitar estos valores, efecto no considerado en este trabajo, pero aun así, no parece razonable limitar el desplazamiento lateral, incluyendo los efectos de ductilidad a valores tan bajos como los del inicio del comportamiento inelástico.

\section{VALORES DE RIGIDEZ EQUIVALENTE PARA EL ANÁLISIS ESTRUCTURAL}

Para determinar los valores de rigidez equivalente se realizan análisis estructurales de cada modelo del marco con la distribución correspondiente de carga lateral. Como se cuenta con los desplazamientos laterales obtenidos en cada piso y en cada ciclo, se modifica mediante prueba y error el $E I_{e q}$ de las vigas y el $E I_{e q}$ de las columnas, para cada ciclo de carga, hasta obtener los desplazamientos según el análisis estructural similares a los obtenidos en cada ciclo del ensayo. Los análisis estructurales que se realizan para cada ciclo son elásticolineales, de manera que se aprecia la forma como se degrada la rigidez secante de la estructura. Los resultados que obtuvieron para la rigidez equivalente en cada marco se grafican en la Figura 13 y 14.

Obsérvese como las vigas varían su rigidez desde valores cercanos a 0,30 hasta valores inferiores a 0,10 para los últimos estados de carga. En el caso de las columnas estas varían la rigidez desde 0,7 hasta valores de 0,10 .

Posteriormente se realizó un análisis inelástico estático no lineal con comportamiento elastoplástico en las rótulas de los extremos de los elementos y con carga lateral incrementada monotónicamente. Para esto se ajustó el valor del $E I_{e q}$ para las vigas y las columnas de manera que se ajustase la rigidez inicial. Los valores obtenidos resultaron ser $0,65 E I_{g}$ para las columnas y $0,27 E I_{g}$ para las vigas en ambos marcos. Con estos valores se realizó el análisis inelástico considerando la modificación de rigidez únicamente por la aparición de las rótulas.

Las curvas inelásticas estáticas se muestran para ambos marcos en las Figuras 15 y 16. 


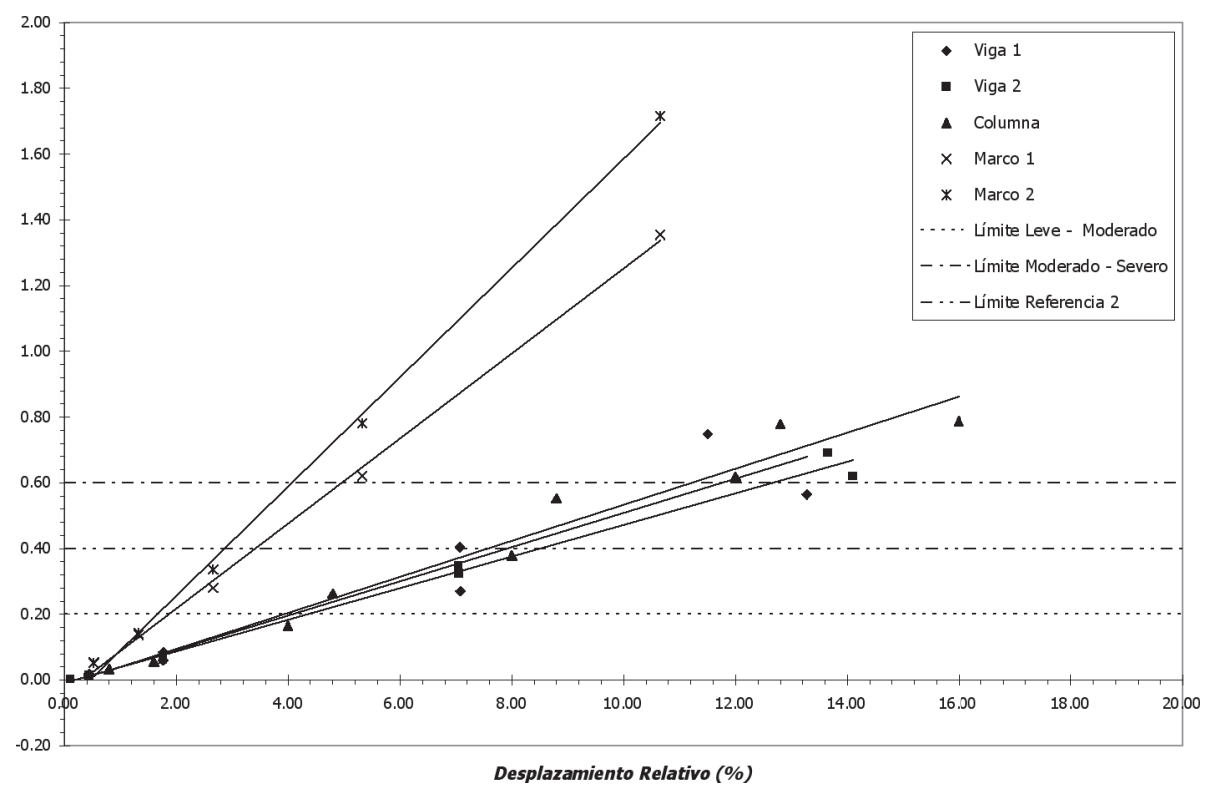

Figura 12. Índice de daño vs desplazamiento relativo

Estas curvas se muestran junto con las correspondientes curvas histeréticas. Las curvas se obtuvieron calculando los $M_{p}$ de los extremos de los elementos como $M_{n}$ según la teoría del concreto reforzado y con $f_{y}$ del diseño especificado. Se observa que las curvas estáticas no alcanzan los máximos de las curvas histeréticas, estas últimas presentan una sobreresistencia sobre la curva estática de más de un $50 \%$ en el caso del marco 1 y del orden de un $30 \%$ en el caso del marco 2. Estos valores de sobre-resistencia de los ensayos cíclicos respecto a los análisis elasto-plásticos estáticos justifican, entre otros aspectos, los valores de sobre-resistencia considerados en las normas sísmicas actuales.

\section{CONCLUSIONES}

1. El rango de índices de daño para determinar el daño descriptivo quedo establecido de manera similar a los propuestos en la literatura técnica; con la salvedad de que los resultados de este trabajo indican de que el daño severo empieza a presentarse para ID igual o mayor a 0,60 .
2. Los elementos individuales presentaron mayor capacidad de deformación inelásticas que los marcos.

3. Desplazamientos relativos del $1 \%$ apenas si causan daño en los marcos y en los elementos.

4. El daño severo se presenta para desplazamientos relativos mayores al $4 \%$ en marcos y mayores al $8 \%$ en elementos individuales.

5. Tanto los elementos como los marcos fueron capaces de disipar una energía cíclica de al menos el doble de la energía que se disipa estáticamente hasta la deformación última.

6. El valor del $E I_{e q}$ para columnas resultó ser $0,65 E I_{g}$ y para las vigas $0,27 E I_{g}$.

7. El análisis inelástico con comportamiento elasto-plástico de las rótulas subestima la capacidad lateral del marco, de manera que los marcos presentan sobre-resistencia respecto a este tipo de análisis del orden de 1,50 . 


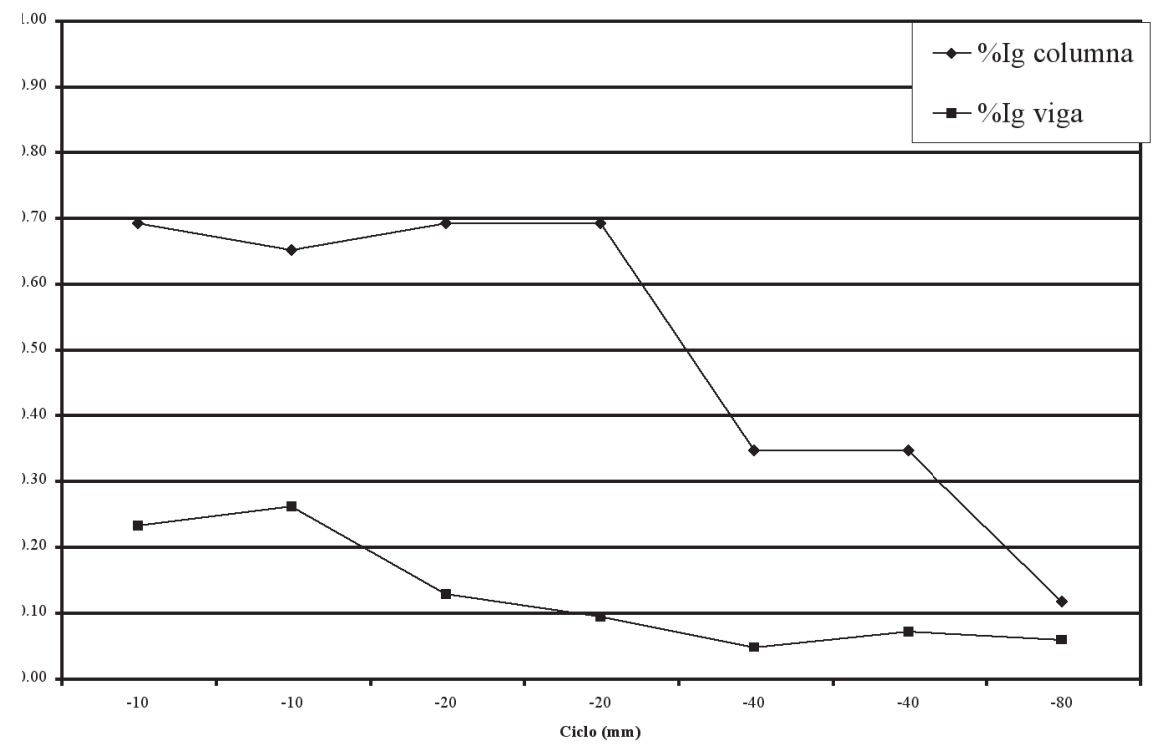

Figura 13. Cambio de rigidez del marco 1, según los ciclos aplicados

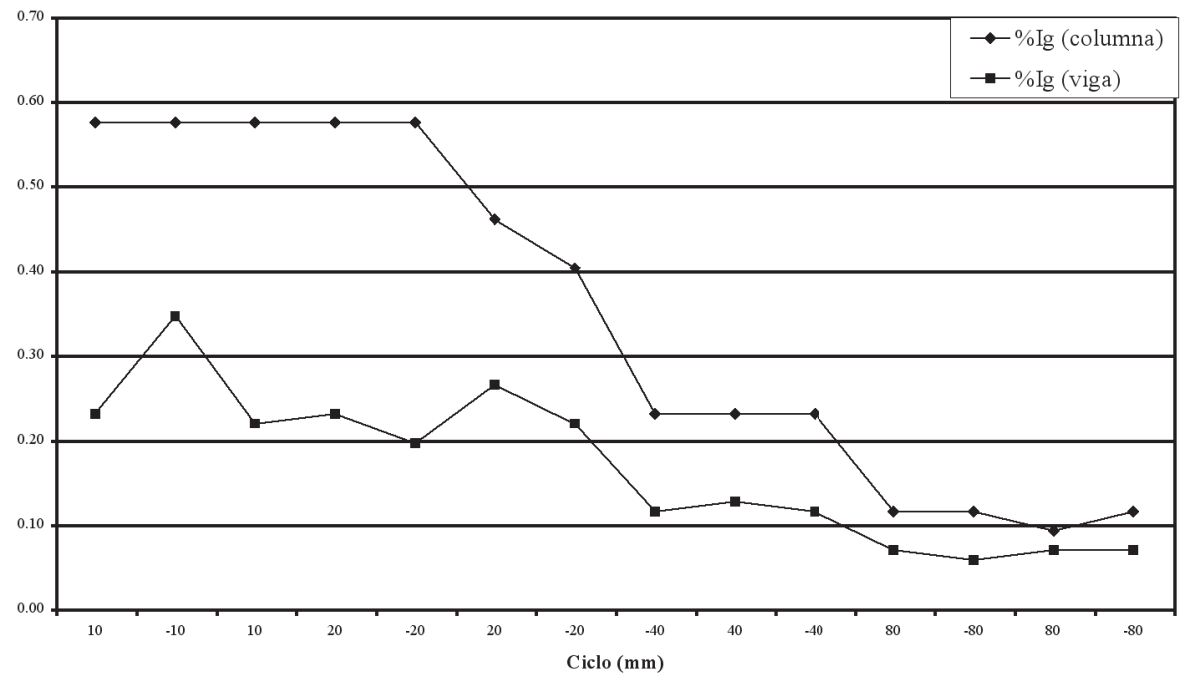

Figura 14. Cambio de rigidez del marco 2, según los ciclos aplicados

\section{AGRADECIMIENTO}

Los autores agradecen al Laboratorio Nacional de Materiales y Modelos Estructurales de la Universidad de Costa Rica por el soporte técnico y científico aportado para realizar esta investigación.

\section{REFERENCIA BIBLIOGRÁFICA}

Park, Y.J. y Ang, A. (1985). Mechanistic Seismic Damage Model for Reinforced Concrete. ASCE Journal, 111(4), 722-739. 


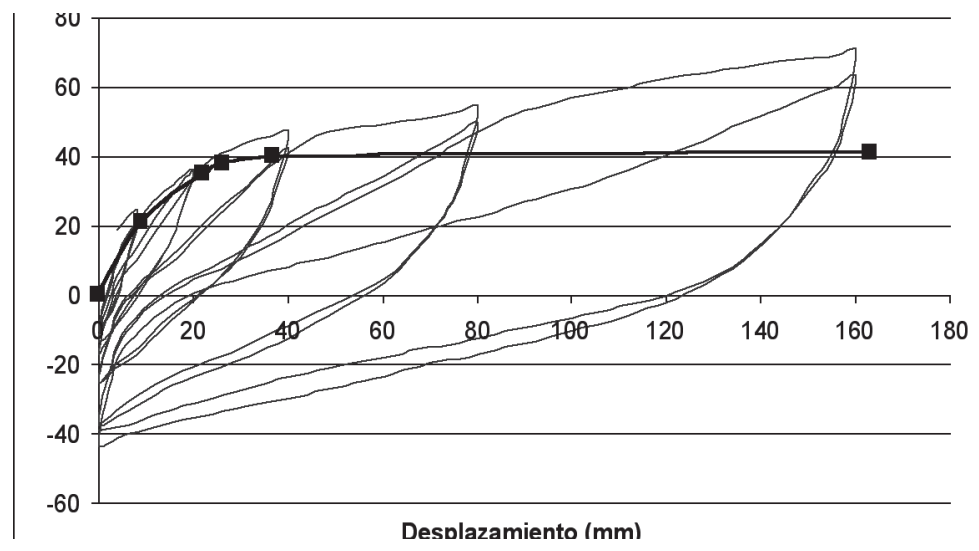

Figura 15. Aproximación del comportamiento del marco 1 por medio del análisis inelástico.

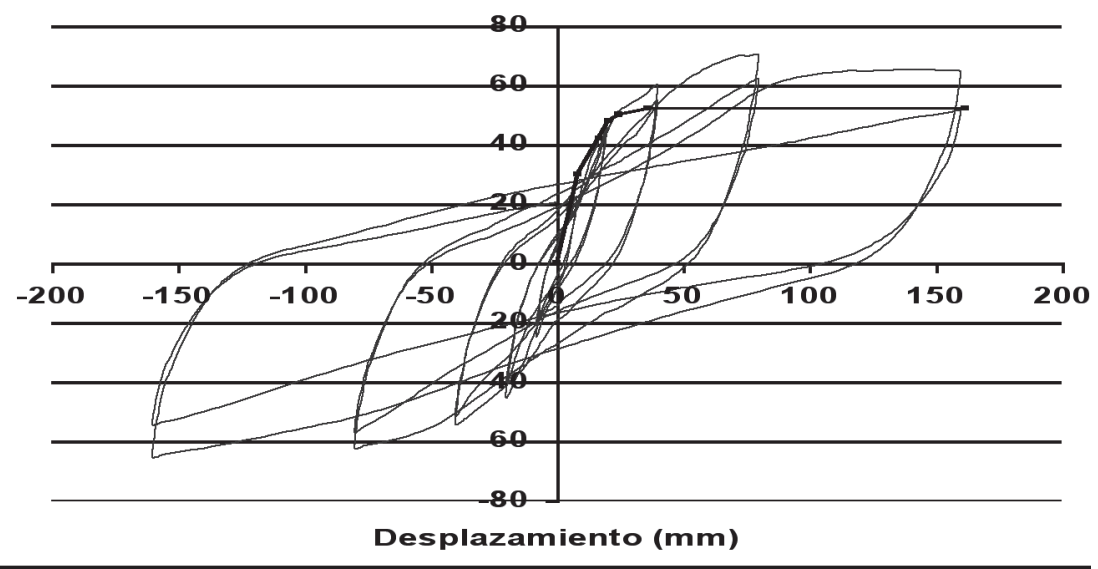

Figura 16. Aproximación del comportamiento del marco 2 por medio del análisis inelástico.

Park, Y.J. y Ang, A. (1985). Seismic Damage Analysis of Reinforced Concrete Buildings. ASCE Journal, 111(4), 740757.

\section{ACI 318-99. (1999). Building Code Requirements} for Structural Concrete and Comentary. ACI, Michigan.

Colegio Federado de Ingenieros y Arquitéctos. (1986). Código Sísmico de Costa Rica.

Vega R., R. (2000). Evaluación del Índice de Daño en Elementos de Concreto Reforzado.
Tesis de Graduación, Universidad de Costa Rica.

Jiménez C., R. (2002). Determinación del Índice de Daño en Marcos de Concreto Reforzado. Tesis de Graduación, Universidad de Costa Rica.

Boza C., J. I (2003). Variación de Rigidez en Marcos de Concreto. Proyecto de Graduación, Universidad de Costa Rica.

Ramírez D., B. (1992). Análisis Comparativo de Indicadores de Daño en Elementos y 
Marcos de Concreto Reforzado. Tesis de Graduación, Universidad de Costa Rica

Chopra, A. K. (1995). Dynamics of Structures. Prentice Hall. New Jersey.

\section{SOBRE LOS AUTORES}

\section{Miguel F. Cruz Azofeifa}

Ph.D. Ingeniero Civil

Profesor Catedrático Escuela de Ingeniería Civil, Universidad de Costa Rica

Teléfono: 2075510

Facsímil: 2242408

Correo electrónico:mfcruz@racsa.co.cr

Juan I. Boza Castro

Licenciado en Ingeniería Civil. Administrador de proyectos en la empresa Gestión y Consultoría Integrada.

Teléfono: 290 95 75/ 3622796

Correo electrónico: Ignacio-boza@gci-ing.com

\section{Ronald Jiménez Castro}

Licenciado en Ingeniería Civil.

Diseñador en la empresa Miguel Cruz y Asociados

Ltda.

Teléfono: 22658 59/ 8327792

Facsímil: 2572574

Correo electrónico:

rojica@costarricense.cr

rjimenezc@cfia.or.cr

\section{Brenda Ramírez Dondi}

Licenciada en Ingeniería Civil

Valuadora en Icicor S.A

Teléfono: 22626 06/355 7626

Correo electrónico: brendondi@hotmail.com

\section{Randall Vega Ramírez}

Licenciado en Ingeniero Civil

Coordinador de obras civiles de la Municipalidad de Alajuela

Teléfono: 44121 25/ 3736546

Facsímil: 4412125 